\title{
MONITORING UNDER ANAESTHESIA, WITH REFERENCE TO SUBARACHNOID HAEMORRHAGE, AND THE T-WAVE AS AN ELECTROCARDIOGRAPHIC MANIFESTATION*
}

\author{
J. W. R. McIntyre, M.R.C.S., L.R.C.P., D. Dobson, M.B., CH.B., B. K. A. WeIR, M.D., \\ R. West, M.D. AND T. R. OverTon, PH.D. †
}

A SUbARACHNOID HAEMORRHAGE during a diagnostic radiologic investigation of patients has been reported on at least four occasions. Even if such a haemorrhage is not immediately fatal its early recognition during routine patient care would be advantageous. Systemic arterial blood pressure and the Lead II EKG are parameters commonly monitored and this report describes changes occurring during simulated subarachnoid haemorrhage in the region of the Circle of Willis in the experimental animal.

The subarachnoid haemorrhage was simulated in Rhesus monkeys by inserting a needle through a hole in the midline of the skull at a point $0.5 \mathrm{~cm}$ cephalad to the nasion and manipulating its tip along the floor of the anterior fossa to a point about $0.75 \mathrm{~cm}$ anterior to the tuberculum sellae so that it lay in the subarachnoid space dorsal to the planum sphenoidale. This is a region that would be contaminated by blood released from an aneurysm in the vicinity of the Circle of Willis. The maneuver was not associated with the development of arterial or electrocardiographic changes. At a suitable time $4.0 \mathrm{ml}$ of fresh autogenous blood was injected through this needle over a period of twenty seconds. Prior to injection the position of the needle was confirmed by x-ray and by the leakage of cerebrospinal fluid. The fact that the blood injection was subarachnoid was often confirmed by the appearance of blood in the cerebrospinal fluid pressure line located in the lumbar region, and invariably at autopsy. The gross characteristics closely resembled the pathological situation in patients succumbing from rupture of an aneurysm. Histologic examination failed to reveal microscopic infarction described by $\mathrm{Smith}^{1}$ as characteristic of this event.

The monkeys were sedated with intraperitoneal sodium pentobarbital and flexometallic endotracheal tubes introduced. Anaesthesia was maintained with nitrous oxide and oxygen from a reservoir in proportions two to one, the animals paralyzed with d-tubocurarine, and artificially ventilated with a Harvard variable phase mechanical ventilator. Three to six hours following the initial sedation the fresh autogenous blood was injected into the vicinity of the Circle of Willis. At this time electroencephalograph monitoring showed a light plane of anaesthesia consistent with the anaesthetic technique.

Fourteen experiments were done and the temperature and acid base status of the animals appear in Table I. These are comparable to those generally accepted

* Supported by Alberta Heart Foundation Grant No. 55-29063-930.

tDepartment of Anaesthesia, and Divisions of Neurosurgery and Biomedical Engineering, University of Alberta, Edmonton, Alberta, Canada. 
TABLE I

The Acid/Base Status of the Animals Immediately Prior to the Subarachnoid INTRODUCTION OF BLOOD

\begin{tabular}{|lcc|}
\hline & $\begin{array}{c}\text { Mean } \\
\text { Value }\end{array}$ & S.D \\
\hline Temperature $\left({ }^{\circ} \mathrm{C}\right)$ & 36.6 & 0.77 \\
\hline $\mathrm{pH}$ & 7.36 & .00 \\
$\mathrm{PCO} 2$ (mm.Hg.) & 41.5 & 7.5 \\
$\mathrm{HCO} 3$ (mEq./L.) & 22.6 & 3.08 \\
$\mathrm{PO}_{2}$ (mm.Hg.) & 132.3 & 40.07 \\
$\mathrm{O}_{2}$ saturation (\%) & 97.6 & 2.19 \\
\hline
\end{tabular}

TABLE II

The Changes in Systematic Arterial Pressure, Lumbar Cerebrospinal Fluid Pressure, and Pulse Rate following the Subarachnoid INTRODUCTION OF BLOOD

\begin{tabular}{|c|c|c|c|c|c|c|c|c|c|}
\hline & $\begin{array}{l}\text { INJECTION OF } \\
\text { SUBARACHNOID } \\
\text { BLOOD }\end{array}$ & & & & & & & & \\
\hline & SECONDS & & 0 & 20 & 40 & 60 & 80 & 100 & 120 \\
\hline $\begin{array}{l}\text { AVERAGE SYSTOLIC } \\
\text { AND DIASTOLIC } \\
\text { ARTERIAL PRESSURE }\end{array}$ & (nmHg) & $\begin{array}{l}\text { Mean } \\
\text { S.D. }\end{array}$ & $\begin{array}{l}118 \\
28.3\end{array}$ & $\begin{array}{l}152 \\
68.4\end{array}$ & $\begin{array}{l}143 \\
43.6\end{array}$ & $\begin{array}{l}131 \\
40.4\end{array}$ & $\begin{array}{l}126 \\
40.2\end{array}$ & $\begin{array}{l}116 \\
37.8\end{array}$ & $\begin{array}{l}110 \\
33.3\end{array}$ \\
\hline PULSE RATE & (BEATS/MIM) & $\begin{array}{l}\text { Mean } \\
\text { S.D. }\end{array}$ & $\begin{array}{l}214 \\
34.3\end{array}$ & $\begin{array}{l}186 \\
44.4\end{array}$ & $\begin{array}{l}159 \\
57.9\end{array}$ & $\begin{array}{l}165 \\
54.4\end{array}$ & $\begin{array}{l}175 \\
46.8\end{array}$ & $\begin{array}{l}179 \\
41.2\end{array}$ & $\begin{array}{l}182 \\
43.0\end{array}$ \\
\hline C.S.F. PRESSURE & (mmHg) & $\begin{array}{l}\text { Mean } \\
\text { S.D. }\end{array}$ & $\begin{array}{l}10 \\
3.4\end{array}$ & $\begin{array}{l}120 \\
76.6\end{array}$ & $\begin{array}{l}70 \\
39.7\end{array}$ & $\begin{array}{l}55 \\
30.9\end{array}$ & $\begin{array}{l}45 \\
27.1\end{array}$ & $\begin{array}{l}37 \\
25.7\end{array}$ & $\begin{array}{l}32 \\
24.1\end{array}$ \\
\hline
\end{tabular}


as normal in conscious resting man. ${ }^{2}$ The changes in systemic arterial pressure, lumbar cerebrospinal fluid pressure, and pulse rate are shown in Table II. During and following the simulated haemorrhage there was a transitory increase in blood pressure and a more sustained elevation in cerebrospinal fluid pressure. The pulse rate tended to slow and in five cases sinus arrhythmia became clearly apparent. Auricular ventricular nodal rhythm or ventricular extrasystoles occurred briefly in eight experiments. The most common electrocardiographic development which occurred in twelve out of fourteen experiments, frequently being present in the absence of any other obvious changes, was elevation of the T-wave. Initially this sometimes approximated the voltage of the QRS complex and persisted in a diminished form during the subsequent three to four hours of the experiment. A combination of events associated with the introduction of blood is illustrated in Figure 1. The animals that were rousable at the termination of the procedures showed peripheral motor defects.

The T-wave represents the repolarization of the ventricles and has the same polarity as the QRS complex. This is so in man and generally held to be so in the Rhesus monkey. ${ }^{3}$ Although a flat or inverted $\mathrm{T}$-wave has been reported to be not uncommon in healthy monkeys, ${ }^{4}$ this finding was unconfirmed in the anaesthetized monkeys presently reported on. The presence of a T-wave depends upon the biochemical and electrical processes occurring in the myocardium, thus any factors influencing cellular energy production and the quantity, distribution,

\section{PAPER SPEED}

\section{$25 \mathrm{~mm} / \mathrm{sec}$.}
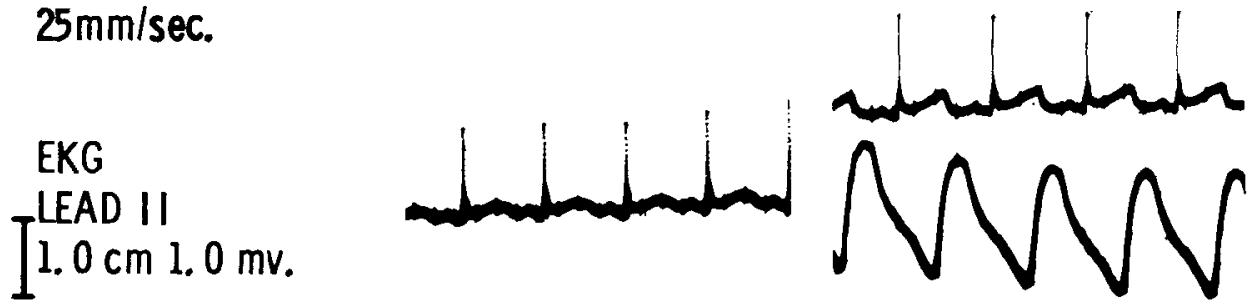

\section{ARTERIAL PRESSURE}
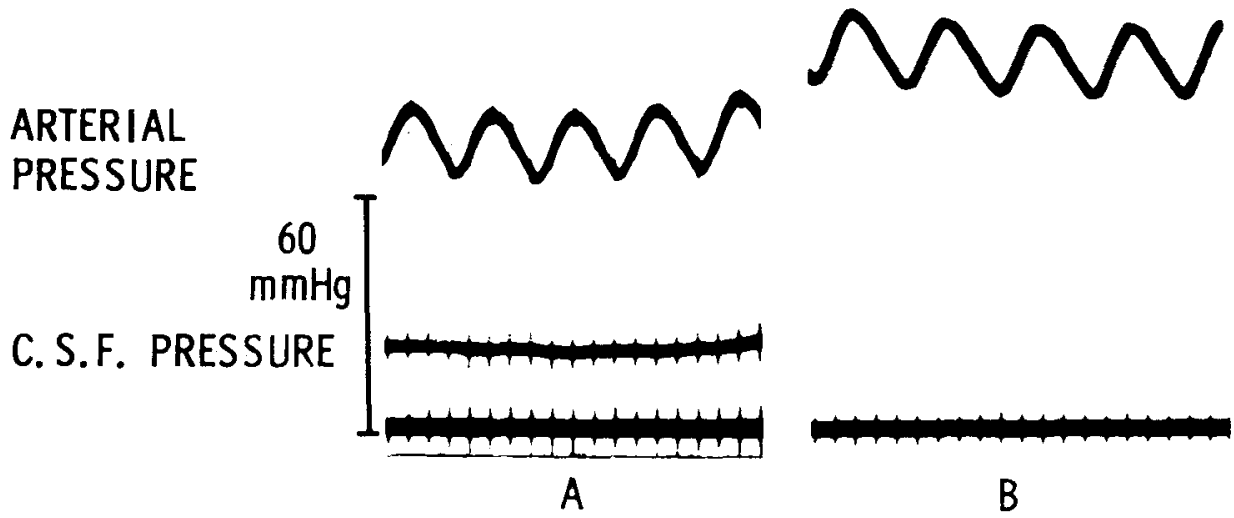

FIGURE 1. Events associated with the subarachnoid introduction of blood. 
and movement of electrolytes influence its shape, polarity and voltage. Such changes can be associated with a wide variety of clinical situations that have been recently documented by Schneider. ${ }^{5}$ Many of these are of particular interest to the anaesthetist and include such things as hyperventilation, posture, carbohydrate intake, and body temperature. Sympathetic and parasympathetic activity exert an influence as do related drugs. Significant also are factors affecting oxygenation as well as acid base balance and sundry other drugs such as glycosides and diuretics. Consequently before a relationship between alteration in the T-wave and possible intracranial event is seriously mooted, the possibility that the anaesthetic technique, the drugs used or other progressive changes in the patient's condition may be responsible for the changes must be excluded.

The incidence of electrocardiographic changes in the clinical occurrence of cerebrovascular accidents has been reviewed by Kreus ${ }^{6}$ who observed elevated T-waves in the early phase after cerebrovascular accident in some cases. The comment is made that previously most authors had been unable to confirm the existence of such waves described in this context by Byer ${ }^{7}$ and Burch., ${ }^{8,9}$ The early appearance of elevated T-waves is certainly consistent with the findings in this study.

It has been stressed that the varying electrocardiographic changes associated with cerebrovascular accidents may also be produced by different forms of cerebral injury. Eichbaum ${ }^{10}$ and his colleagues performed a series of studies in which the intracranial pressure of dogs artificially ventilated under pentobarbital sodium anaesthesia was increased, the brain inevitably being subjected to differing types of localized stimulation. They referred to alterations of varying character in the T-wave as the most common and characteristic electrocardiographic disturbance. The precise mechanism of the arrhythmias was not completely elucidated, but it was demonstrated pharmacologically and by cross circulation experiments that sympathetic nervous influences rather than vagal activity is of paramount importance. ${ }^{11}$ This finding has been supported by subsequent workers. ${ }^{12}$ Its cause might be a direct or induced interference with the cerebral cardiac regulation independent of the primary site of cerebral compression or direct stimulation of the Circle of Willis which has sympathetic associations in its nerve supply. ${ }^{13}$ Thus the electrocardiographic changes produced by intracranial events such as haemorrhage or increased pressure and their value for monitoring purposes may be modified by the sympathomimetic or sympatholytic actions of the anaesthetic drugs or such drugs administered ancillary to the anaesthesia.

In conclusion, if these experiments can be legitimately related to the clinical situation then it appears that the systemic blood pressure changes occurring at the time of a subarachnoid haemorrhage may not be noticed during routine intermittent sphygmomanometry performed manually. As far as monitoring the Lead II electrocardiogram is concerned alterations in rhythm may be infrequent. A more common occurrence is alteration in the shape of the T-wave which may indicate the occurrence of a subarachnoid haemorrhage or other developing intracranial event at this time. 


\section{REFERENCES}

1. SMITH, B. Cerebral pathology in subarachnoid haemorrhage. J. Neurol. Neurosurg. Psychiat. 26: 535 (1963).

2. Munson, E. S.; Gillespie, J. R.; \& Wagman, I. H. Respiratory blood gases and pH in two species of unanaesthetized monkeys. J. of Applied Physiol. 28: 108 (1970).

3. Singh, R.; Chakravarti, R. N.; Chhuttani, R. N.; \& Wahi, P. L. Electrocardiographic studies in rhesus monkeys. J. of Applied Physiol. 28: 346 (1970).

4. Ruskin, A. \& RigDon, R. H. The electrocardiogram of normal and malaria-infected monkeys. J. Lab. Clin. Med. 34: 1105 (1949).

5. Schneider, R. G. \& Lyon, A. E. Use of oral potassium salts in the assessment of r-wave abnormalities in the electrocardiogram: A clinical test. Am. Heart J. 77: 721 (1969).

6. Kreus, K. E.; Kemila, S. J.; \& Takala, J. K. Electrocardiographic changes in cerebrovascular accidents. Acto Med. Scand. 185: 327 (1969).

7. Byer, E.; Ashman, R.; \& Toth, L. A. Electrocardiogram with large upright t-waves and long QT intervals. Am. Heart J. 33: 796 (1947).

8. Burch, G. E.; Meyers, R.; \& ABknskov, J. A. A new electrocardiographic pattern observed in cerebrovascular accidents. Circulation. 9: 719 (1954).

9. Burgh, G. E. \& PhILlips, J. H. The large upright T-wave as an electrocardiographic manifestation of intracranial disease. Southern Med. J. 61: 331 (1968).

10. Eichbaum, F. W.; Gazetra, B. H.; Bissetti, P. C.; \& Pereira, C. B. Electrocardiographic disturbances following acute increase of intracranial pressure. Zeitschrift fur die gesamte experimentelle Medizin. 139: 721 (1965).

11. Eichbaum, F. W.; Gazetta, B. H.; \& Bissetti, P. C. Mechanism of encephalogenic heart injury. Zeitschrift fur die gesamte experimentelle Medizin. 139: 735 (1965).

12. OfFERHAus, L. \& Gool, J, van. Electrocardiographic changes and tissue catecholamines in experimental subarachnoid haemorrhage. Cardjovasc. Res. 3: 433 (1969).

13. Poor, J. L. Vasocardiac effects of the Circle of Willis. Arch. of Neur. \& Psych. 78: 357 (1957). 